\title{
Effects of a few food diet in attention deficit disorder
}

\author{
C M Carter, M Urbanowicz, R Hemsley, L Mantilla, S Strobel, P J Graham, E Taylor
}

\begin{abstract}
Seventy eight children, referred to a diet clinic because of hyperactive behaviour, were placed on a 'few foods' elimination diet. Fifty nine improved in behaviour during this open trial. For 19 of these children it was possible to disguise foods or additives, or both, that reliably provoked behavioural problems by mixing them with other tolerated foods and to test their effect in a placebo controlled double blind challenge protocol. The results of a crossover trial on these 19 children showed a significant effect for the provoking foods to worsen ratings of behaviour and to impair psychological test performance. This study shows that observations of change in behaviour associated with diet made by parents and other people with a role in the child's care can be reproduced using double blind methodology and objective assessments. Clinicians should give weight to the accounts of parents and consider this treatment in selected children with a suggestive medical history.

(Arch Dis Child 1993; 69: 564-568)
\end{abstract}

The effect of food and food additives on hyperactivity remains controversial. Initial suggestions by Feingold ${ }^{1}$ implicating food additives and natural salicylates were largely unconfirmed by controlled studies of hyperactive children, ${ }^{2}$ though single case control studies showed the effect of artificial colours in individual children. ${ }^{3}$

The occurrence of adverse skin, gut, and

Institute of Child

Health, London,

Behavioural Sciences

Unit

C M Carter

M Urbanowicz

L Mantilla

P J Graham

Department of

Immunology

S Strobel

Institute of Psychiatry, London, Department of Psychology R Hemsley

MRC Child Psychiatry Unit E Taylor

Correspondence to: Ms Christine Carter, Dietetics Department Queen Elizabeth Hospital fo Children, Hackney Road, London E2 8PS.

Accepted 23 July 1993 other physical reactions to foods such as milk and wheat stimulated speculation that such foods could also produce adverse behavioural effects. A double blind controlled study ${ }^{4}$ conducted by a team including two of the present authors (CMC, PJG), suggested that foods and additives could be shown to affect hyperactive behaviour adversely. This was based on ratings by parents, but not shown on objective psychological testing. Criticism of this study related to (a) the correct diagnosis of hyperactivity, (b) the selected study population, and (c) the high tartrazine challenge dose. Since then three studies with limited scope looking only at food dyes have been published ${ }^{5-7}$ with contradictory results. Kaplan et al, in a placebo controlled study of a diet excluding additives, chocolate, caffeine, and any other foods suspected by parents, found that more than half their 24 preschool subjects showed an improvement. ${ }^{8}$ Egger et al found marked effects of a few food diet in an open trial, but did not proceed to test the response in a blind trial as their design led them instead to use the open response as a measure of the effectiveness of a hyposensitisation procedure. ${ }^{9}$

In the absence of clear confirmation or refutation of the results of the earlier study and in an attempt to meet some of the criticisms, we undertook the current study using a similar design, but with improved methodology and clearly defined outcome measures.

\section{Methods}

Children were referred by general practitioners, paediatricians, and psychiatrists to a special diet and behaviour clinic set up at the Hospital for Sick Children. All children accepted for the study met DSM III criteria for attention deficit disorder with hyperactivity, ${ }^{10}$ were between 3 and 12 years old, and had IQs above 70 . Where children were already on diets their parents were asked to take them off the diet for a week before the initial interview. This interview included a systematic medical and social history, a standardised psychiatric interview, a school report, Conners' parent and teacher scales, ${ }^{11}$ a cognitive assessment using the standard Wechsler intelligence scale for children - revised, ${ }^{12}$ or Wechsler preschool and primary scale of intelligence, ${ }^{13}$ a Neale reading test, ${ }^{14}$ and an assessment of family relationships. ${ }^{15}$

\section{Treatment procedures}

\section{FIRST PHASE: FEW FOOD DIET}

The children were put on a restricted (or 'few foods') diet for a period of three to four weeks. The foods allowed were typically two meats (often lamb and turkey), two carbohydrate sources (rice and potato), two fruits (often banana and pear), a range of root and green vegetables, bottled water, sunflower oil, and milk free margarine. ${ }^{16}$ This diet was varied to suit the child's preferences and to avoid foods already suspected, or foods for which the child had a particular craving or dislike. If there was no improvement by the end of the second week the diet was changed or further restricted for the last week. Failure to improve by the end of this period meant that the child left the trial at this point.

SECOND PHASE: OPEN REINTRODUCTION

Where behavioural improvement occurred, foods and additives were reintroduced at the rate of one a week in normal amounts and 
incorporated into the diet if there was no relapse. If the parent was worried about the possibility of a bad reaction, the amounts were stepped up to normal over a few days.

Food additives (colours, flavours, and preservatives) were usually introduced as mixtures in additive-containing foods such as ham, bacon, sausages, coloured sweets, and drinks with colour, preservatives, and flavours. In an effort to obtain a clearer idea of the components of the foods responsible for any adverse reaction, artificial colours were then given where possible using capsules containing $6.5 \mathrm{mg}$ mixed colours. These were usually given in increasing amounts, starting with one capsule on the first day and increasing rapidly to no more than four capsules a day by the end of one week. If the children refused the capsules, these colours were mixed with melted chocolate or carob bars.

THIRD PHASE: DOUBLE BLIND OR EXPERIMENTAL PHASE

Where possible, children were asked to enter a double blind, crossover, placebo controlled trial of reintroduction of one or more incriminated foods or additives. This stage was offered to all children who were receiving an acceptable and adequate diet, whose parents agreed, and where a provoking item could be given in sufficient amount and be adequately disguised in a food known to be tolerated (to act as excipient and placebo). The order in which incriminated foods and placebo were given was allocated randomly by CMC (by the toss of a coin). Each was given for one week with a two week washout period between active and placebo phases.

Material was prepared individually for each child and the amount of incriminated food given was based on the amount which seemed to be needed to provoke problems on open reintroduction. For example, between 120 and $200 \mathrm{ml}$ of cows' milk was given daily disguised in a milk substitute (for example soya milk) for provocation, while milk substitute was given as placebo. Artificial colours were given disguised in capsules rendered opaque with iron oxide. Each capsule contained $6.5 \mathrm{mg}$ mixed colours (1 $\mathrm{mg}$ tartrazine, $1 \mathrm{mg}$ sunset yellow, $1 \mathrm{mg}$ quinoline yellow, $0.5 \mathrm{mg}$ carmoisine, $0.5 \mathrm{mg}$ brilliant blue, $0.5 \mathrm{mg}$ erythrosine, $0.5 \mathrm{mg}$ green $\mathrm{S}, 0.5 \mathrm{mg}$ indigocarmine, $0.5 \mathrm{mg}$ amaranth, and $0.5 \mathrm{mg}$ ponceau $4 \mathrm{R}$ with glucose as filler). The number of capsules given varied, but no child received more than $26 \mathrm{mg}$ colouring daily, which is roughly equivalent to four to five packs of children's sweets a day. Capsules containing glucose alone were given as placebo. For children who would not swallow the capsules, the colours were disguised in carob or chocolate as already described. Benzoic acid and sodium metabisulphite (25 $\mathrm{mg}$ increasing to $50 \mathrm{mg}$ during the week) were given dissolved in a suitable non-provoking drink. Drinks were prepared and immediately frozen, to be thawed and consumed on a daily basis by the child. Orange juice was disguised in a mixture of pureed pears and pineapple juice. Apple juice was disguised in pineapple and apricot juice. Chocolate was disguised in carob confectionery. Most of the children received more than one provoking item. For example, one child, who was receiving a very restricted diet, received food colours disguised in vegetable soup as well as apple juice disguised in carrot juice.

The preparations were made and coded by CMC and given to the family by MU. At this time CMC took no part in the management and everyone else remained blind to the order in which active and placebo foods were given.

\section{PSYCHOLOGICAL ASSESSMENT}

Systematic assessment of behaviour was undertaken using a battery of outcome measures at three points in time: at entry to the experimental phase, at the end of the first experimental period (one week later), and at the end of the second period (a further three weeks later). These measures had shown differences between hyperactive and non-hyperactive children and between stimulant drug and placebo in previous research. ${ }^{17}$

Behaviour was assessed with Conners' behavioural rating scale for parents ${ }^{11}$ and with a global rating of severity of behaviour problems made by the parent with most contact with the child. (It was not possible to gather teacher ratings on a satisfactory number of children mainly because of the parents' wish to carry out the trial during the school holidays.)

Behaviour during testing was directly observed by the psychologist and rated on dimensions of fidgetiness, restlessness (involving movements of the whole body), and inattentiveness. These observations were summed into a single scale of hyperactive behaviour. A paired associate learning test ${ }^{18}$ was used to measure new learning: the score is the number of errors during learning of a list to criterion. Impulsiveness versus reflectiveness was assessed using the revised form of the matching familiar figures test. ${ }^{19}$ For children under 6 years of age we used a simplified form of the test developed by Cohen and Minde. ${ }^{20}$ The measures taken from each child are the mean latency to first response and the number of errors made for each stimulus.

\section{Analysis}

The analysis followed from the study's design as a two period crossover trial in which each child acted as his or her own control. ${ }^{21}$ Continuous measures were tested for differences of means with $t$ tests. Square root transformations were carried out before significance testing because of some skew in the measures; the means, differences, and standard errors reported in table 3 are based on untransformed data. Order effects (that is, first $v$ second administration) and treatment effects (that is, active food $v$ placebo) were tested with paired $t$ tests; interactive effects were tested with comparisons of the two order groups (active first $v$ placebo first) on the difference between active and placebo. If a measure was unavailable for 
an individual child (for example, if the Conners' scale had been incompletely filled in by parents), then the child was excluded from the analysis for that measure only.

The one categorical measure - the global ratings made by the parents - was tested (in view of small numbers) by Fisher's exact probability test with a one tailed level of significance set at $0 \cdot 05$. One tailed significance testing was justified because of the study's position as a replication of previous work, so that there could be no doubt of its having set out to test the specific hypothesis of foods worsening the child's behaviour.

\section{Subjects}

Eighty four of the 130 children referred to the clinic were judged to meet the admission criteria and their parents agreed to participate in the trial. Of these, 78 children ( 69 boys and nine girls) completed the initial period on a few food diet; the remaining families were unable to tolerate the regimen.

The 78 children who completed the first phase of the trial ranged in age from 3 to 12 years. The range of IQ was between 72 and 135 (average 104). Forty seven were referred directly by their general practitioners, 10 by psychiatrists, three by neurologists, 14 by paediatricians, and four by psychologists. The parents of 23 children reported asthma (which was under control with drugs) or hay fever, or both; the parents of 38 children reported eczema or skin rashes; the parents of 12 children reported headaches; the parents of 30 children reported gastrointestinal symptoms; and the parents of two reported fits. Fourteen of the children had no physical symptoms. Many of these symptoms were mild and managed by the general practitioner. Twenty four of the 78 children who completed the first phase had been seen by specialists for physical symptoms: 12 for asthma, five for gastrointestinal problems, one for diabetes, two for fits, three for eczema, six for 'allergies', and one for enuresis.

Of the 78 children, 24 were exposed to adverse psychosocial situations such as discordant intrafamilial relations, inconsistent

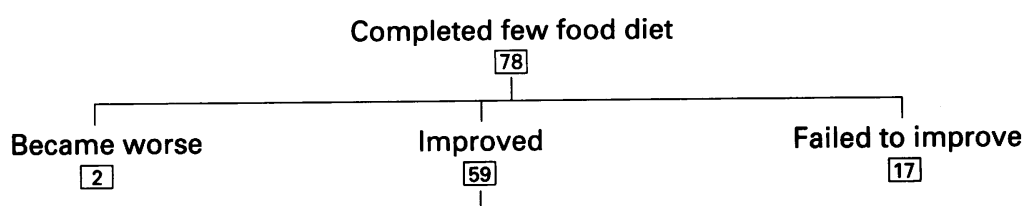
Reintroduction with relapses, 'responders'
$\begin{gathered}\text { Reintroduction, no relapses } \\ 3\end{gathered}$

(Considered for double blind phase)

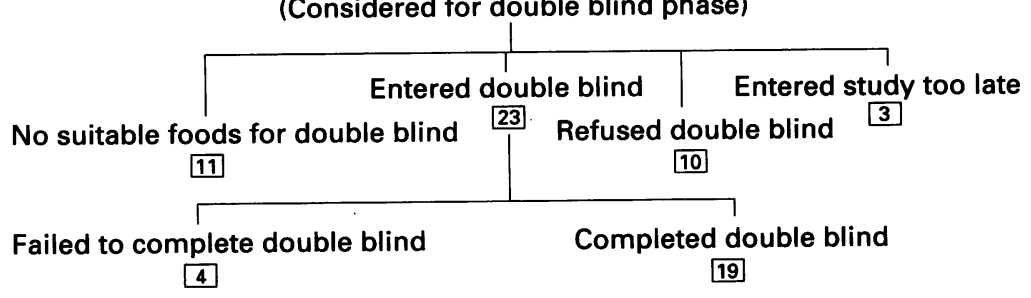

Figure 1 Allocation of children to the trials. Values in boxes are numbers of children.
Table 1 Foods most commonly implicated for the 47 responders during open reintroduction

\begin{tabular}{|c|c|c|c|}
\hline & $\begin{array}{l}\text { No } \\
\text { tested }\end{array}$ & $\begin{array}{l}\text { No } \\
\text { reacting }\end{array}$ & $\begin{array}{l}\% \\
\text { Reacting }\end{array}$ \\
\hline \multicolumn{4}{|l|}{ One or more additive- } \\
\hline Chocolate & $\begin{array}{l}32 \\
37\end{array}$ & $\begin{array}{l}22 \\
28\end{array}$ & $\begin{array}{l}70 \\
64\end{array}$ \\
\hline Cows' milk & 45 & 26 & 64 \\
\hline Orange & 35 & 20 & 57 \\
\hline Cows'cheese & 31 & 14 & 45 \\
\hline Wheat & 47 & 21 & 45 \\
\hline Other fruits & 47 & 17 & 36 \\
\hline Tomato & 35 & 8 & 22 \\
\hline Egg & 38 & 7 & 18 \\
\hline
\end{tabular}

The number of children who tried each of these foods and the number who responded adversely are shown. No child tried every food. Some parents did not introduce foods that were every food. Some parents did not introduce foods that were
disliked, whereas others refused to introduce additive-containing foods that they felt would cause a problem.

parental control, or anomalous family situations. Forty three children were already receiving some dietary restriction when first referred to the study.

\section{Results}

Seventy eight children completed the few food diet. The parents of 59 of these children $(76 \%)$ felt there had been a worthwhile improvement in behaviour, two children (3\%) became worse, and $17(22 \%)$ did not respond. The 59 children whose behaviour had improved (fig 1) entered the second phase of the trial, the open sequential reintroduction of foods to establish target foods for the double blind phase. For three $(5 \%)$ of the 59 children it was not possible to provoke a relapse with any food and they remained well. For the parents of nine $(15 \%)$ children the demands of the diet proved impossible to meet and they abandoned it. The foods implicated in the deterioration of behaviour are therefore described for the remaining 47 children (referred to hereafter as responders).

A large number of foods were implicated during the reintroduction phase and table 1 shows the number of children reacting adversely to the most common provoking foods. All the relapses to food included worsening of behaviour except for four relapses caused by cows' milk and two by cheese, which gave rise to physical symptoms only. These behavioural problems were sometimes accompanied by the reappearance of the physical symptoms which were reported to have improved on the few food diet.

It is difficult to obtain a complete picture of intolerance to specific food additives as they often occur in mixtures in manufactured foods. Just four children were found to react only to foods containing additives. When food colours were suspected, we asked parents to give their children colour capsules. Sixteen agreed to do this; three children were not affected, two had behavioural and physical symptoms, eight had behavioural problems only, and three had physical symptoms only. Of 19 who tried cola drink, 16 reported problems.

\section{DOUBLE BLIND PHASE}

Eleven of the 47 responders reacted adversely to foods which could not be given in the 


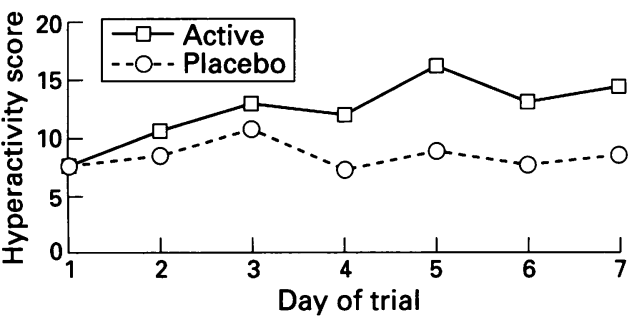

Figure 2 Daily Conners' scale scores (parents' hyperactivity ratings). The mean scores, on the hyperactivity factor of the Conners' behaviour rating scale, are separately shown for the placebo period and the period during which a potentially active food was given.

double blind phase. Usually this was because the amount (for example of wheat) that induced symptoms was too great to disguise, or because no suitable placebo and excipient could be identified (for example, for cola). The parents of a further 10 children refused because of particular family circumstances at that time and three children had entered the study too late to reach this stage.

Twenty three children were accepted into the double blind phase of the trial. On the first day of each phase the families were asked to guess whether they had been given the provocation or placebo food. The appearance and taste did not make the foods obvious; $50 \%$ of the guesses were correct and 50\% were wrong.

Four of the children who met the criteria for entering the double blind phase did not complete it satisfactorily (two were withdrawn by their families and two broke their diet). Nineteen children therefore formed the group whose course in the crossover trial will now be described.

The global rating made by parents favoured the placebo period in 14 children. The active period was favoured in three children and no preference was expressed in two others; these five children were combined as treatment failures. There were fewer such failures than predicted by chance (Fisher's exact test probability 0.03 ).

Figure 2 shows the course over a week for the group mean on the short form of the Conners' scale in the active and placebo phases. The differences at the end of each phase were greatest for the items 'restless', 'disturbs others', 'cries often', and 'temper outbursts', suggesting a possibly greater effect on irritability than on attention deficit.

Table 2 shows behavioural ratings and test scores. Each of the outcome measures was tested for order, treatment, and interaction effects as described earlier. No effect of order,

Table 2 Test measures during blind trial

\begin{tabular}{|c|c|c|c|c|}
\hline Test* & $\begin{array}{l}\text { Mean }(S D) \\
\text { pretrial } \\
\text { result }\end{array}$ & $\begin{array}{l}\text { Mean }(S D) \\
\text { active } \\
\text { result }\end{array}$ & $\begin{array}{l}\text { Mean (SD) } \\
\text { placebo } \\
\text { result }\end{array}$ & $\begin{array}{l}\text { Difference (SE) } \\
\text { between } \\
\text { active-placebo } \\
\text { result }\end{array}$ \\
\hline $\begin{array}{l}\text { CPRS score } \\
\text { Observation } \\
\text { PALT errors } \\
\text { MFF errors } \\
\text { MFF time (sec) }\end{array}$ & $\begin{array}{c}8 \cdot 1(7 \cdot 7) \\
0 \cdot 60(0 \cdot 3) \\
15 \cdot 2(14) \\
1 \cdot 3(0 \cdot 7) \\
12 \cdot 3(11 \cdot 5)\end{array}$ & $\begin{array}{c}13.9(9 \cdot 1) \\
0.80(0 \cdot 4) \\
14.9(14) \\
1.6(0.7) \\
9.0(9.5)\end{array}$ & $\begin{array}{c}8 \cdot 8(7 \cdot 4) \\
0.57(0 \cdot 4) \\
14 \cdot 6(13) \\
1.4(0 \cdot 8) \\
11.9(12 \cdot 3)\end{array}$ & $\begin{array}{l}5.2(2.5) \\
0.23(0.1) \\
0.31(1.5) \\
0.21(0.1) \\
2.9(1.0)\end{array}$ \\
\hline
\end{tabular}

Observations were made by the psychologist testing the children.

CPRS = Conners' parent rating scale; $P A L T=$ paired associate learning test; $M F F=$ matching familiar figures test. or interaction between order and treatment was fourd.

Behavioural ratings by parents on the final day of each treatment period showed a statistically significant effect of the foods $(p<0.05)$. Errors on the paired associate learning test were not significantly different between groups, but there was a difference on the matching familiar figures test for latency and errors $(p<0.01)$. The psychologist's behavioural observations also showed differences for the scale of hyperactive behaviour $(p<0.01)$, with the greatest difference on the item rating fidgetiness.

These results suggest that children whose behaviour is 'diet responsive' on an open trial can also be shown to respond by a blind observer using standardised tests.

\section{RESPONDERS $v$ NON-RESPONDERS}

Of great value to the clinician would be information about which children are likely to respond to diet and some hints may be obtained from the open phase of the trial. The 47 responders and 17 non-responders did not differ in terms of age or sex, socioeconomic status, number of physical symptoms, or thirst. There was, however, a marked difference between the two groups in the number of children on a restricted diet before the study. The parents of $90 \%$ of the responders had already noticed a reaction to food, whereas only $6 \%$ of the non-responders had done so. Cravings were reported by $85 \%$ of the parents of responders and $30 \%$ of non-responders. Dietary management also seemed less likely to produce a change where there were discordant marital relations (present in $13 \%$ of responders, $53 \%$ of non-responders)

In the blind phase of the trial, children had already been selected as 'responders', so the prediction of response at this stage is less feasible. It was, however, possible to divide the 16 children with complete rating scales into six with trivial or absent physical symptoms and 10 whose physical symptoms were judged to be significant. The difference between the means for active and placebo was calculated for parental ratings, separately for those with and without physical symptoms. Those with symptoms (mean (SD) difference $5.5(10 \cdot 8)$ ) were not significantly different from those without (mean (SD) difference 4.7 $(9 \cdot 6))$.

\section{Discussion}

This trial indicates that diet can contribute to behaviour disorders in children and that this effect can be shown in a double blind, placebo controlled trial. The effects of diet were not as large as in some stimulant drug trials, but may have been underestimated by the design as amounts of food given blind were necessarily small. The important conclusion is that the parents' reports of a behaviour change with diet can, in a selected group of children, be confirmed by double blind, placebo controlled trial with objective tests. 
It is not possible to conclude that diet is a satisfactory treatment for all hyperactive children. Although efforts were made to recruit an unbiased sample in our second study, this was only partially successful. Our group still included a high proportion of children with physical symptoms and of parents who were particularly interested in following a dietary approach.

Diagnostic uncertainties also lead to some doubt about the group of children to whom the results can be generalised. We chose the DSM III definition of attention deficit disorder with hyperactivity as a robust and widely studied definition. Some people, however, will apply the word 'hyperactivity' either to a wider group of children with high scores on questionnaire ratings, or to a narrower group of children with hyperkinetic disorder who are also more biologically impaired.22 It is not likely that the precise psychiatric manifestation is the key to identifying a diet sensitive group, however. Severity of hyperactivity did not predict outcome in this series. European clinicians should note that the group with 'attention deficit' in this report would often receive a clinical diagnosis of conduct disorder. ${ }^{23}$

The ways in which diet worked remain unclear. Toxic, pharmacological, or allergic mechanisms could be involved, and the physiological effects of different foods may vary. It is conceivable that foods might induce changes in brain perfusion similar to those reported in attention deficit disorder by Lou et $a l{ }^{24}$ These results argue against the notion that the only mechanism involved is the 'placebo effect' of expectation and suggestion, and testing this was a main purpose of the study. The results do not exclude the possibility of indirect mechanisms via bodily symptoms rather than effects on brain function. The finding of a similar effect size in children with and without physical symptoms is circumstantial evidence against such an explanation, but does not rule it out because full physical evaluation might reveal worsening of physical illness due to foodstuffs with behavioural changes secondary to feeling ill and because the children had already been selected as responders by the open phase of the trial.

The treatment, as applied in this study, has disadvantages. It is a difficult and exacting regimen which puts a considerable strain on the whole family. It is not yet clear whether modified diets can also be effective. In this study and our previous work, ${ }^{4}$ the same foods were found to be most commonly implicated. It may therefore be possible to devise a less restricted diet with similar levels of success. It seems clear, from the small number of children reacting only to additives at the open stage, that an additive free diet by itself would be of little benefit.

There are some indications from this study that the symptoms showing change are not the attention deficit that is considered to be the core of hyperactivity, but rather irritability. Many parents commented after the few food diet phase that their children had become more manageable and more amenable to reasoning rather than less active or better able to concentrate.

In conclusion, this confirms and extends results obtained in an earlier study ${ }^{4}$ that diet can be shown to affect some children in a double blind placebo controlled trial, but that dietary management is difficult to carry out. It is still not clear how generally applicable such a treatment might be within a general group of hyperactive children. There are indications that if parents notice some effects of diet, efforts should be made to support their exploration of exclusion diets. Further research could focus on the development and assessment of a modified diet based on the avoidance of the most commonly implicated foods, on the possibility of mediation by physical symptoms, and on any physical basis of the behavioural reaction in children showing sensitivity to specific foods.

The authors are grateful to Action Research and the Trustee Savings Bank for financial support, to Rowntrees plc for supplying food colours, to Lilly Industries Ltd for supplying
capsules for food colours, and to the children and families involved in the study who coped enthusiastically with the demands we made on them.

1 Feingold BF. Hyperkinesis and learning disabilities linked to artificial food flavours and colors. Am F Nurs 1975; 75: 797-803.

2 Taylor E. Toxins and allergens. In: Rutter $M$, Casaer P, eds. Biological risk factors for psychosocial disorders. New York: Academic Press, 1992: 219-32.

3 Weiss B, Williams JH, Margen S, et al. Behavioural response to artificial food colours. Science 1980; 207: 1487-9.

4 Egger J, Carter CM, Graham PJ, Gumley D, Soothill JF. Controlled trial of oligoantigenic treatment in the hyperkinetic syndrome. Lancet 1985; i: 540-5.

5 David TJ. Reactions to dietary tartrazine. Arch Dis Child 1987; 62: 119-22.

6 Rowe KS. Synthetic food colourings and 'hyperactivity': a double blind crossover study. Australian Paediatric fournal 1988; 24: 143-7.

7 Pollock I, Warner JO. Effect of artificial food colours on childhood behaviour. Arch Dis Child 1990; 65: 74-7.

8 Kaplan BJ, McNicol J, Conte RA, Moghadam HK. Dietary replacement in preschool-aged hyperactive boys. Pediatrics 1989; 83: 7-17

9 Egger J, Stolla A, McEwen LM. Controlled trial of hyposensitisation in children with food induced hyperkinetic syndrome. Lancet 1992; 339: 1150-3.

10 American Psychiatric Association. Diagnostic and statistical manual of mental disorders. 3rd Ed. Washington, DC: APA, 1980.

11 Conners CK. Rating scales for use in drug studies with children. Psychopharmacol Bull 1973; 9: 24-8.

12 Wechsler D. The Wechsler intelligence scale for children revised. New York: Psychological Corporation, 1974.

13 Wechsler D. The Wechsler preschool and primary scale of intelligence. New York: Psychological Corporation, 1969.

14 Neale MD. Neale analysis of reading ability. 2nd Ed. New York: Macmillan, 1968

15 Quinton D, Rutter M, Little C. Institutional rearing, parenting difficulties and marital support. Psychol Med 1984; 14: 107-24.

16 Carter CM, Egger J, Soothill FJ. A dietary management of severe childhood migraine. Human Nutrition: Applied Nutrition 1985; 39A: 294-303.

17 Taylor E. Attention deficit. In: Taylor E, ed. The overactive child. London: MacKeith Press/Blackwell, 1986: 73-106. (Clinics in developmental medicine No 97.)

18 Swanson J, Kinsbourne M. Stimulant related state-dependent learning in hyperactive children. Science 1976; 192: 1354-6.

19 Cairns E, Cammock T. Development of a more reliable version of the matching familiar figures test. Developmental sion of the matching familiar
Psychology 1978; 14: 555-60.

20 Cohen NJ, Minde K. The 'hyperactive syndrome' in kindergarten children. Comparison of children with pervasive and situational syndromes. $\mathcal{f}$ Child Psychol Psychiatry 1983; 24: 443-56.

21 Hills $M$, Armitage $P$. The two period cross-over clinical trial. Br f Clin Pharmacol 1979; 8: 7-20.

22 Taylor E, Sandberg S, Thorley G, Giles S. The epidemiology of childhood hyperactivity. Oxford: Oxford University Press, 1991. (Maudsley monographs No 33.)

23 Prendergast M, Taylor E, Rapoport JL, et al. The diagnosis of childhood hyperactivity: a US-UK cross-national study of DSM-III and ICD-9. $\mathcal{f}$ Child Psychol Psychiatry 1988; 29: 289-300.

24 Lou HC, Henriksen L, Bruhn P. Focal cerebral dysfunction in developmental learning difficulties. Lancet 1990; 335: 8-11. 